\title{
A INFLUÊNCIA DA LIDERANÇA NO CLIMA ORGANIZACIONAL DE UMA EMPRESA
}

\author{
DE DEFENSIVOS AGRÍCOLAS
}

\section{THE INFLUENCE OF LEADERSHIP IN THE ORGANIZATIONAL CLIMATE OF A COMPANY OF}

\author{
AGRICULTURAL DEFENSIVES
}

Maria Izabel Batista da Rocha ${ }^{1}$ http://orcid.org/0000-0002-8040-1466

Vanessa Piovesan Rossato ${ }^{2}$ http://orcid.org/0000-0001-7165-4712

Roger da Silva Wegner ${ }^{3}$ http://orcid.org/0000-0002-2034-8034

Michel Barboza Malheiros ${ }^{4}$ http://orcid.org/0000-0001-7076-4258 Julia Tontini ${ }^{5}$ http://orcid.org/0000-0001-8509-8665

Recebido em: 23 jul. 2020 Aceito em: 24 jul. 2020

Como citar este artigo: DA ROCHA, M. I. B.; ROSSATO, V. P.; WEGNER, R. da S.; MALHEIROS, M. B.; TONTINI, J. A INFLUÊNCIA DA LIDERANÇA NO CLIMA ORGANIZACIONAL DE UMA EMPRESA DE DEFENSIVOS AGRÍCOLAS: THE INFLUENCE OF LEADERSHIP IN THE ORGANIZATIONAL CLIMATE OF A COMPANY OF AGRICULTURAL DEFENSIVES. Revista Visão: Gestão Organizacional, Caçador (SC), Brasil, v. 10, n. 2, p. 137-157, 2021. DOI: 10.33362/visao.v10i2.2326. Disponível em: https://periodicos.uniarp.edu.br/index.php/visao/article/view/2326.

Resumo: As constantes mudanças em que as empresas vêm sofrendo ao longo dos anos, têm

\footnotetext{
1 Graduação em Administração pela Universidade Federal de Santa Maria, Brasil(2017). E-mail: bel.singular@hotmail.com.

${ }^{2}$ Graduação em Administração pela Universidade Federal de Santa Maria (UFSM). Mestranda em Administração pelo Programa de Pós-Graduação em Administração (PPGA) na UFSM. E-mail: vanessapiovesan@yahoo.com.br.

${ }^{3}$ Graduação em Administração pela Universidade Federal de Santa Maria (UFSM). Especialista em Estatística e Modelagem Quantitativa pela UFSM. Mestre em Engenharia de Produção pela UFSM. Atualmente é Doutorando em Administração pelo Programa de Pós-Graduação em Administração (PPGA) na UFSM. E-mail: rswegnerr@gmail.com.

${ }^{4}$ Graduação em Administração pela Universidade Federal de Santa Maria (UFSM). Mestrando em Administração pelo Programa de Pós-Graduação em Administração (PPGA) na UFSM. E-mail: malheirosmb@gmail.com.

${ }^{5}$ Graduação em Administração pela Universidade Federal de Santa Maria (UFSM). Mestranda em Administração pelo Programa de Pós-Graduação em Administração (PPGA) na UFSM. E-mail: ju-tontini@hotmail.com.
} 
destacado as áreas de gestão de pessoas as quais tem estado em constante crescimento, pois os gestores passaram a investir no capital humano para encontrar o caminho do sucesso das organizações. Diante dessa importância que é dada aos funcionários o referido trabalho tem por objetivo, analisar a influência da liderança no clima organizacional em uma empresa de defensivos agrícolas. Para obtenção dos resultados o estudo buscou identificar os fatores internos e externos de influência no clima organizacional, baseando-se no modelo proposto por Bispo (2006). A pesquisa teve uma amostra vinte e cinco colaboradores da empresa analisada, os quais responderam um questionário com perguntas estruturadas, que foram analisadas por meio da análise de frequência e da técnica de regressão simples. Ao término da pesquisa, identificou-se que o estilo de liderança que predomina na organização é a democrática, a qual exerce uma influência positiva no clima organizacional. Apesar da maioria dos resultados a respeito do clima serem positivos, a pesquisa apresenta alguns pontos que podem ser aperfeiçoados na relação da empresa com o empregado.

Palavras-Chave: Gestão de pessoas. Liderança. Clima organizacional.

Abstract: The constant changes in which companies have been suffering over the years, have highlighted the areas of people management which have been in constant growth, as managers started to invest in human capital to find the path of success for organizations. In view of this importance that is given to the employees, this work aims to analyze the influence of leadership on the organizational climate in a pesticide company. To obtain the results, the study sought to identify the internal and external factors influencing the organizational climate, based on the model proposed by Bispo (2006). The survey had a sample of twenty-five employees from the analyzed company, who answered a questionnaire with structured questions, which were analyzed through frequency analysis and simple regression technique. At the end of the research, it was identified that the leadership style that predominates in the organization is democratic, which has a positive influence on the organizational climate. Although most of the results regarding the climate are positive, the survey presents some points that can be improved in the company's relationship with the employee.

Keywords: People management. Leadership. Organizational climate.

\section{INTRODUÇÃO}

Com o mundo globalizado as empresas estão em constante crescimento e a administração tem tido um papel fundamental nessas mudanças. É notável que a chance de sucesso se torne maior, quando a empresa é bem administrada, e todos os pilares que sustentam a administração estejam em sintonia. Tendo em vista esse crescimento e as mudanças constantes, as empresas cada vez mais têm se preocupado com investimentos no capital humano das organizações. Barbieri (2016) destaca que dentro das organizações, o respeito pelas diversidades e pelas necessidades psicológicas e motivacionais dos seus colaboradores e também de seus clientes tem se tornado fatores de grande importância.

Tendo em vista o comportamento dos indivíduos dentro das empresas, o desempenho do líder possui um papel fundamental para que esse clima mantenha-se satisfatório, pois é por 
meio dos estilos de liderança que as organizações vão demonstrar qual o significado que dão a cada um de seus colaboradores. Ademais, o estilo de gestão pode fazer com que a empresa mantenha uma comunicação mais transparente com seus liderados ou para que os objetivos da organização sejam mantidos somente dentro da alta gestão, o que pode trazer um clima de autoritarismo dentro do ambiente organizacional (GUERRA; TARTAROTTI; CAMARGO, 2018).

Segundo Giustina, Gasparetto e Lunkes, (2020), o indivíduo que desenvolve o papel de líder influencia a conduta de um ou mais liderados e a competência de liderar está profundamente ligada com o processo de motivação, em uma situação de dependência mútua entre o líder e liderados. Sousa e Cappellozza, (2019) ainda destacam que só há liderança quando há subordinados que são influenciados ou aceitam a influência para seguir o líder por algum motivo. O líder tem um papel fundamental para que essa entrega aconteça, porque é através dele que o colaborador vai sentir a segurança que o ambiente de trabalho está lhe proporcionado (ABELHA; CARNEIRO; CAVAZOTTE, 2018; GIUSTINA; GASPARETTO; LUNKES, 2020).

Diante disso, o objetivo desse trabalho consiste em identificar a influência do estilo de liderança no clima organizacional em uma empresa de defensivos agrícolas. Assim, desenvolver um clima organizacional saudável pode ser a chave do sucesso para a empresa conseguir alcançar seus objetivos. Um clima sadio além de diminuir os conflitos entre os colaboradores faz com que a organização se torne mais transparente. O colaborador que se sente parte da sua organização, tende a ter mais empenho no trabalho conseguindo atingir os melhores resultados. Ademais, as pesquisas de clima organizacional, podem criar vínculos mais fortes entre os colaboradores e a organização, evidenciando maiores interações, o que facilita um funcionamento eficaz da organização (MATTOS, 2019).

Ademais, o estudo do clima organizacional e liderança podem fazer com que os seus dirigentes e colaboradores consigam identificar os pontos positivos e negativos que possam estar trazendo influência no caminho que a organização está tomando, e se necessário, aplicar ações corretivas nesses pontos a melhorar. Além disso, o estilo de liderança também pode ser revisto se necessário e o mais importante é sentir como está a integração do líder com os seus liderados, pois essa parceria estando saudável pode trazer bons resultados à organização, através da motivação e incentivo dos talentos humanos.

\section{REFERENCIAL TEÓRICO}

\section{LIDERANÇA}

O papel do líder tem sido muito importante nos ambientes coorporativos e organizacionais, pois eles serão responsáveis por gerir os recursos principais da organização 
que são as pessoas (GIUSTINA; GASPARETTO; LUNKES, 2020). Barbieri (2016) destaca que "os gestores atuais devem responder a várias questões: como construir um clima de confiança e abertura; como descobrir o potencial dos colaboradores; como treinar e desenvolver as pessoas".

A liderança transacional caracteriza-se sempre com base em uma transação de troca entre o líder e o liderado. Esta relação de troca pode se dar por através de uma natureza psicológica, econômica ou política (BURNS, 1978). Ainda conforme Hitt et al. (2007), a liderança transacional compreende em uma troca onde os liderados realizam os desejos dos líderes para obterem as recompensas desejadas. Para Bass (1985) o líder transacional baseia-se na relação líder-subordinado para realização das tarefas (SOUSA; CAPPELLOZZA, 2019).

Para Maximiano, (2012) a liderança transacional ou negociadora tem como base, desde a sua origem, que a competência e o desempenho devem ser retribuídos através de algum critério. Em sua visão esses líderes recorrem às necessidades primárias e aos interesses dos seus subordinados prometendo gratificações para conseguirem que eles trabalhem no cumprimento de suas metas (LIMA; GOMES, 2017). Maximiano (2007) apresenta algumas recompensas materiais que podem ser oferecidas pelo líder transacional como: aumentos salariais; promoções; liberalidade e autonomia e no uso do seu tempo; atendimento de solicitações relacionadas a designação para outros projetos, dispensas e transferências; prêmios de acordo com o desempenho, como o "diploma do melhor colaborador do mês" ou uma participação nos lucros e resultados e Custeio de programas de treinamento.

Soto (2010) destaca em sua obra que os líderes transacionais são aqueles que orientam e motivam os seus liderados no rumo das metas estabelecidas através da explanação dos requisitos de papéis e tarefas (RODRIGUES et al., 2019). Um líder transformador inicia criando um olhar do que deveria ser o melhor de sua organização, repartição ou grupo de trabalho. A visão dirige o administrador que busca o melhor caminho para encontrar os resultados desejados como produtividade, desempenho e qualidade (GUERRA; TARTAROTTI; CAMARGO, 2018).

O líder transformacional possui um perfil mais comunicativo, um olhar mais claro que dá autonomia aos seus seguidores, reduz a burocracia irrelevante, incentiva à cooperação em equipe (RODRIGUES et al., 2019). Além disso, consente a participação dos colaboradores nas decisões, possibilita treinamentos, condensam as políticas da organização, buscando alcançar as metas organizacionais (HITT; MILLER; COLELLA, 2007; SOBRAL; FURTADO; ISLAM, 2019).

Soto (2010) caracteriza os líderes transformacionais como sendo líderes que permitem uma importância individualizada e estímulos intelectuais e possuem carisma (VERSIANI et al., 2019). De acordo com Bass (1985), esta modalidade de liderança é a única que propicia aos liderados um desempenho esplêndido, pois busca majorar a consciência da equipe e da empresa, alinhando as expectativas pessoais e organizacionais, proporcionando a 
evolução dos indivíduos (LIMA; GOMES, 2017).

Já Robbins (2002) expõe que os líderes transformacionais são carismáticos, capazes de influenciar seus subordinados à realização de seus interesses próprios para o bem da empresa e de proporcionar influências profundas sobre os indivíduos com quem labora (ABELHA; CARNEIRO; CAVAZOTTE, 2018). Robbins (2002) complementa ainda que estes líderes transformam a maneira dos liderados olharem a realidade, orientando-os a descobrir soluções novas para problemas antigos, estão sempre alertas às necessidades de desenvolvimento de cada um de seus subordinados e são capazes de estimular os liderados a dedicarem todos os seus esforços em benefício dos propósitos da equipe (GUERRA; TARTAROTTI; CAMARGO, 2018).

Para Maximiano (2012) o líder carismático é aquele que tem seguidores fieis por proporcionar recompensas de conteúdo moral, fazendo com que seus seguidores superem seus interesses pessoais e trabalhem esplendidamente para realizar a meta, causa ou missão da organização. Para obter esse grau de entrega e realização, os líderes carismáticos dão atenção especial para às potencialidades e às necessidades seus liderados (ABELHA; CARNEIRO; CAVAZOTTE, 2018).

A abordagem da liderança carismática é determinada pelas habilidades heroicas e excepcional as quais os liderados conferem ao líder, sendo que grande parte da realização dos seus aprendizados é dedicado ao reconhecimento das características e comportamentos que distancia os líderes carismáticos dos outros líderes (RODRIGUES et al., 2019).

\section{CLIMA ORGANIZACIONAL}

A definição de clima organizacional consiste no olhar dos trabalhadores perante o ambiente de trabalho no que se refere a perspectiva individual e grupal. Desse modo, o clima organizacional consiste na percepção do local de trabalho tendo como base as experiências internas entre os colaboradores. Destaca-se que o clima organizacional está sempre se modificando, sendo impactado pelos critérios subjugados de cada colaborador. Além disso, as pesquisas de clima organizacional servem de suporte à medida que conecta a organização com a equipe de trabalho, evidenciando a realidade momentânea daquela empresa (MATTOS, 2019).

Para Coda (1997), o clima organizacional caracteriza-se de forma mais ampla, onde o clima reflete uma inclinação ou aptidão a respeito de até que ponto as dificuldades da organização e das pessoas que fazem parte dela estariam verdadeiramente sendo acompanhadas, tornando-se esse aspecto um dos indicadores da eficácia organizacional (COSTA; SILVA, 2020). Um administrador eficiente dá prioridade a desenvolver um ambiente positivo nas organizações, de tal maneira que as pessoas trabalhem em um esforço comum de forma mais eficaz, tendo chance de desenvolver suas competências, realizando suas aspirações 
profissionais e atingindo recompensas e os reconhecimentos adequados.

As características desses ambientes são as seguintes: (a) Existe ampla comunicação dentro de toda a organização na totalidade dos sentidos: do maior para o menor, do menor para o maior e lateralmente; (b) Todos tem honestidade e integridade absoluta em tudo o que dizem e fazem; (c) Trazer a tona todos os problemas e tentar resolve-los é realmente um interesse legítimo; (d) Os dirigentes estão verdadeiramente interessados em escutar o ponto de vista dos outros, principalmente de seus dirigidos; (e) Dedicarem-se ao trabalho como verdadeiras equipes é do interesse de todos. Todas essas características fazem com que se crie um clima organizacional saudável trazendo sensação de segurança a todos que fazem parte dessa organização (LACOMBE, 2008).

Para que uma organização possua um clima organizacional saudável é necessário que ela considere as necessidades, percepções e sentimentos dos colaboradores (MATTOS, 2019). Por conseguinte, destaca-se que o capital humano está crescentemente constituindo pilares para melhor desempenho organizacional e que a coesão entre os interesses profissionais e pessoais, está muitas vezes, subordinada no nível de comprometimento dos trabalhadores. Desse modo, uma das ferramentas para gestão desse capital humano consiste nas pesquisas de clima organizacional, posto que pode evidenciar o aprimoramento de talentos.

\section{A INFLUÊNCIA DO ESTILO DE LIDERANÇA NO CLIMA ORGANIZACIONAL}

Wenski e Soavinsky (2013) pesquisaram a influência do líder no clima organizacional de uma empresa multinacional de reflorestamento de pinus a empresa possui unidades no Brasil e em outros três países, a pesquisa foi realizada em uma das filiais localizada no estado do Paraná, onde conta com 90 colaboradores, entre administrativos, industriais e florestais. 0 estudo em questão foi feito através de uma pesquisa quantitativa que utilizou um questionário contendo 20 questões, compondo-se de 19 fechadas e objetivas e uma questão aberta.

As questões utilizadas por Wenski e Soavinsky (2013) buscou identificar a posição dos colaboradores no que diz respeito à segurança no trabalho, relação dos colaboradores e empresa, relacionamento entre a equipe, satisfação, reconhecimento, meios de comunicação da organização. Para tanto, levou em consideração o relacionamento dos colaboradores com o líder, ao avaliar o respeito, feedback, a clareza na comunicação de ordens e elogios recebidos do líder. Conclui-se que o clima da empresa de reflorestamento é bom, que o respeito entre os colaboradores e liderados é mutuo, o que faz com que o clima seja satisfatório para todos, podendo relacionar essa satisfação como o sucesso da empresa, pois se conclui que um colaborador está motivado quando possui um melhor desempenho.

Radaelli (2011) fez um estudo de caso que apontou o estilo de liderança presente na empresa Sucesso Ltda, que visou diagnosticar de que modo o estilo de liderança pode afetar o clima organizacional. Nesse estudo Radaelli (2011) utilizou-se de uma entrevista com o diretor 
geral da empresa e aplicou um questionário em uma amostra de 30 colaboradores. Revelou-se que o estilo de liderança predominante na organização é a autocrática, da mesma forma concluiram que o clima organizacional é considerado bom para ambos, entretanto alguns apontamentos como ação das lideranças, comunicação dos objetivos organizacionais, participação dos colaboradores, e a vitalidade da organização obtiveram os maiores percentuais negativos evidenciando o descontentamento dos colaboradores, o que pode estar afetando de forma negativa um clima organizacional favorável.

\section{PROCEDIMENTOS METODOLÓGICOS}

Esse estudo trata-se de uma pesquisa descritiva, em que foi relatado todos os dados encontrados na empresa estudada com uma abordagem quantitativa que se utilizou de questionário para a pesquisa de clima e determinação do estilo de liderança de um estudo de caso pois foi realizado em uma empresa de defensivos agrícolas, onde visou buscar os fatores internos e externos que influenciam no clima organizacional da mesma, e a percepção do seu quadro de colaboradores, quanto ao clima que a organização Ihe proporciona.

A pesquisa de clima organizacional foi realizada em uma empresa de defensivos agrícolas localizada no Rio Grande do Sul, a qual conta com um quadro funcional de 26 colaboradores. O presente estudo foi realizado com 25 dos colaboradores da empresa, ficando somente uma colaboradora sem responder os questionamentos, pois no momento da aplicação do questionário encontrava-se em licença maternidade.

Para análise do clima organizacional, foi utilizado o modelo de Bispo (2006), conforme apresentado na seção de Referencial teórico. O modelo de questionário desenvolvido para o estudo do clima foi uma adaptação feita por Biegelmeyer et. al., (2015) na pesquisa de fatores internos e externos que influenciam o clima organizacional. Biegelmeyer et. al., (2015) também se basearam no modelo proposto por Bispo (2006) que aplicou um questionário para a execução da pesquisa de clima organizacional. Bispo (2006) realizou a pesquisa em organizações da área de recursos humanos, esta atividade foi realizada com os profissionais e também se utilizou da literatura referente este tema. As questões de liderança foram fundamentadas com base na literatura relacionada com estilos de liderança, as quais exclusivamente determinam a liderança autocrática, democrática e liberal.

O instrumento de coleta de dados foi um questionário estruturado com vinte e duas variáveis, distribuídas em trinta e nove questões, sendo elas duas questões abertas, três questões gerais de múltipla escolha e trinta e quatro questões fechadas de múltipla escolha. As perguntas foram divididas entre o levantamento dos fatores internos e externos que podem influenciar no clima organizacional da empresa e o estilo de liderança.

Nas três primeiras questões foi perguntado o gênero, a faixa etária, escolaridade e o 
tempo de serviço do colaborador na empresa. Os funcionários também foram solicitados a dar uma nota geral para o clima organizacional da empresa. Para os demais questionamentos foi utilizada uma escala de 5 pontos cujas possibilidades de resposta foram: (1) Discordo Totalmente (2), Discordo (3) Indiferente, (4) Concordo (5), concordo totalmente.

No levantamento dos fatores internos de influência do relacionamento entre os funcionários e a empresa, os colaboradores foram indagados com 19 questões, já no levantamento dos fatores externos, utilizou-se 13 questões, para mensuração de questões relacionadas à liderança utilizou-se 6 questões.

Para a análise dos dados levantados dos fatores internos e externos que influenciam no clima organizacional, foi utilizado o software Microsoft Excel 2010 para uma análise descritiva, a qual definiu as variáveis demográficas e as frequências de resposta de todas as perguntas. Desse modo, as variáveis observadas foram interpretadas buscando as informações necessárias para analisar e trabalhar o problema em questão.

Para fazer a análise dos dados foi utilizada a técnica de regressão. A análise de regressão que compreende exclusivamente uma variável explicativa é chamada de regressão simples, enquanto a análise que compreende duas ou mais variáveis explicativas é chamada regressão múltipla (HAIR jr. et al., 2005).

A análise de regressão aponta como ou em que grau as variáveis estão associadas entre si. Todos os resultados sobre causa e efeito devem basear-se no entendimento dos indivíduos que têm o melhor conhecimento da aplicação. Esse estudo utilizou análise de regressão linear simples. Na regressão linear simples, qualquer observação compreende-se em dois valores: um para a variável independente e outro para variável dependente.

O Modelo de regressão linear simples é:

$$
\text { 1a Equação: } \quad y=b 0+b 1 x+e
$$

Onde, b0 e b1 descrevem os parâmetros do modelo, e (a letra grega épsilon) significa uma variável aleatória que se designa erro aleatório ou parcela de erro. A parcela de erro é encarregda pela variabilidade em y que não pode ser explanada pela relação linear entre x e y (Anderson. et al.,2017).

A equação de regressão linear simples é:

2a Equação: $\quad E(y)=b 0+b 1 x$

Os livros mais modernos a respeito de análise de regressão constantemente redigem a equação de regressão como:

$$
\text { 3a Equação: } \quad E(y \mid x)=b 0+b 1 x
$$

Para resaltar que ela produz o valor médio de y para dado valor de x (Anderson. et al.,2017). 


\section{RESULTADOS}

Essa seção está dividida em três partes. Desse modo, a primeira etapa revela a caracterização da amostra estudada. A segunda parte trabalha com os Fatores Internos de influência no clima organizacional. Em seguida, Fatores Externos de influência no clima organizacional. Posteriormente, apresentou-se os estilos de liderança e por fim, uma análise de regressão linear simples.

\section{CARACTERIZAÇÃO DA AMOSTRA}

Tabela 1: Caracterização da amostra

\begin{tabular}{|c|c|}
\hline Gênero & Relativo (\%) \\
\hline Masculino & 80 \\
\hline Feminino & 20 \\
\hline \multicolumn{2}{|l|}{ Faixa etária } \\
\hline Até 20 anos & 8 \\
\hline Entre 21 a 30 anos & 33 \\
\hline Entre 31 a 40 anos & 17 \\
\hline Entre 41 a 50 anos & 13 \\
\hline Acima de 50 anos & 29 \\
\hline \multicolumn{2}{|l|}{ Escolaridade } \\
\hline Ensino fundamental incompleto & 20 \\
\hline Ensino fundamental completo & 8 \\
\hline Ensino médio incompleto & 4 \\
\hline Ensino médio completo & 40 \\
\hline Ensino superior incompleto & 20 \\
\hline Ensino superior completo & 28 \\
\hline \multicolumn{2}{|l|}{ Tempo na empresa } \\
\hline Até 3 meses & 1 \\
\hline Até 10 meses & 2 \\
\hline 1 ano & 4 \\
\hline 2 anos & 2 \\
\hline 3 anos & 3 \\
\hline 5 anos & 1 \\
\hline 6 anos & 1 \\
\hline 7 anos & 1 \\
\hline 8 anos & 1 \\
\hline 9 anos & 2 \\
\hline 11 anos & 1 \\
\hline 12 anos & 1 \\
\hline 13 anos & 2 \\
\hline 17 anos & 1 \\
\hline
\end{tabular}




\begin{tabular}{l|l}
\hline 18 anos & 2 \\
\hline
\end{tabular}

Fonte: dados da pesquisa, 2017.

A partir da amostra considerada, percebe-se que a empresa é constituída na sua maioria de funcionários do sexo masculino que correspondem a $80 \%$ que corresponde a vinte pessoas e $20 \%$ do sexo feminino que corresponde a cinco pessoas. Pode-se observar que com relação à idade dos colaboradores questionados, a empresa conta com colaboradores de todas as faixas etárias, mas tem seu maior número dividido entre os colaboradores de 21 à 30 anos e os acima de 50, o que demonstra que a empresa não busca um perfil pré determinado com a idade, tendo espaço para todos as faixas etárias, como pode-se observar nos dados relacionados a seguir, de 21 à 30 anos 33\% corresponde 9 pessoas, acima dos 50 anos 29\% corresponde sete pessoas, 31 à 40 anos 17\% corresponde a quatro pessoas 41 a 50 anos 13\% corresponde a três pessoas e até 20 anos $9 \%$ corresponde a duas pessoas.

$\mathrm{Na}$ amostra pesquisada, nota-se que a escolaridade dos respondentes é relativamente baixa, sendo que $80 \%$ correspondendo a dez pessoas possui o ensino médio completo (até 3 anos), seguidos pelos $28 \%$ corresponde a cinco pessoas que já tem ensino superior e $10 \%$ que corresponde a sete pessoas que estão com o curso superior em andamento. Apresenta ainda no ensino fundamental completo (até 8 a série) $5 \%$ correspondendo a duas pessoas, ensino médio incompleto (até 3ำ ano) 2\% corresponde a uma pessoa. A empresa não possui colaboradores que tenham o ensino fundamental incompleto (até 8a série).

O tempo de serviço de cada respondente ficou dividido da seguinte maneira: um colaborador com três meses de serviço, dois com dez meses, quatro com um ano, dois com dois anos, três com três anos, com cinco, seis, sete e oito anos existe um colaborador, dois possuem nove anos, onze, doze um colaborador para cada ano, com treze anos tem dois colaboradores, dezessete anos existe um funcionário e com dezoito anos de experiência profissional na empresa encontra-se dois colaboradores. Nota-se que a maioria dos colaboradores estão na empresa por mais de cinco anos, ou seja, têm períodos longos de serviço na empresa. Esse resultado pode demonstrar que o clima seja satisfatório, não tendo grande rotatividade de colaboradores.

\section{FATORES INTERNOS DE INFLUÊNCIA NO CLIMA ORGANIZACIONAL}

Nessa etapa buscou-se investigar os fatores internos de influência no clima organizacional. Para isso, foram utilizadas onze variáveis, as quais foram adaptadas do questionário utilizado por Bispo (2011). Para cada questão o colaborador tinha cinco opções de resposta, sendo elas 1)Discordo totalmente (DT) 2) Discordo (D), 3) Indiferente (I), 4) Concordo (C) e 5) Concordo totalmente (CT).

Tabela 2: Fatores internos da influência da liderança no clima organizacional 


\begin{tabular}{|c|c|c|c|c|c|}
\hline \multicolumn{6}{|l|}{ Vida Profissional } \\
\hline & $1(\mathrm{DT})$ & $2(D)$ & $3(1)$ & 4C & $5(\mathrm{CT})$ \\
\hline 1 - Sinto orgulho de trabalhar nesta empresa. & & & & 9 & 16 \\
\hline $\begin{array}{l}2 \text { - Sinto me satisfeito com a atividade que desempenho nesta } \\
\text { empresa. }\end{array}$ & & & & 10 & 15 \\
\hline 3 - Acho que a empresa me oferece um bom plano de carreira & & 1 & 2 & 12 & 10 \\
\hline $\begin{array}{l}4 \text { - Costumo indicar esta empresa como alternativa de emprego } \\
\text { para meus amigos e parentes. }\end{array}$ & 1 & 3 & 7 & 6 & 8 \\
\hline $\begin{array}{l}5 \text { - Considero que estou obtendo sucesso na minha carreira e na } \\
\text { minha vida profissional. }\end{array}$ & & & 1 & 14 & 10 \\
\hline $\begin{array}{l}6 \text { - A empresa me proporciona cursos e treinamentos suficientes } \\
\text { para o exercício das minhas atividades. }\end{array}$ & & 3 & & 8 & 14 \\
\hline \multicolumn{6}{|l|}{ Ambiente de trabalho } \\
\hline $\begin{array}{l}7 \text { - O ambiente de trabalho favorece a execução das minhas } \\
\text { atividades na empresa. }\end{array}$ & & & 1 & 5 & 19 \\
\hline $\begin{array}{l}8 \text { - Tenho um bom relacionamento com os meus colegas de } \\
\text { trabalho }\end{array}$ & & & & 6 & 19 \\
\hline \multicolumn{6}{|l|}{ Assistência aos funcionários } \\
\hline $\begin{array}{l}9 \text { - A empresa oferece assistência médica ou odontológica } \\
\text { adequada as minhas necessidades. }\end{array}$ & 6 & 7 & 5 & 5 & 2 \\
\hline \multicolumn{6}{|l|}{ Burocracia } \\
\hline $\begin{array}{l}10 \text { - A burocracia adotada na empresa favorece a execução das } \\
\text { minhas atividades na empresa. }\end{array}$ & 1 & 2 & 5 & 12 & 5 \\
\hline \multicolumn{6}{|l|}{ Cultura Organizacional } \\
\hline $\begin{array}{l}11 \text { - A Cultura Organizacional (tradições, práticas e costumes } \\
\text { adotados na empresa) favorece a execução das minhas } \\
\text { atividades na empresa. }\end{array}$ & & 1 & 3 & 14 & 7 \\
\hline \multicolumn{6}{|l|}{ Estrutura Organizacional } \\
\hline $\begin{array}{l}\text { 12- O meu chefe imediato é a pessoa mais indicada para a } \\
\text { função que ocupa.. }\end{array}$ & & & & 10 & 15 \\
\hline $\begin{array}{l}13 \text { - Estou satisfeito com a estrutura hierárquica (chefes e } \\
\text { subordinados) a que estou vinculada. }\end{array}$ & & & 1 & 9 & 15 \\
\hline \multicolumn{6}{|l|}{ Valorização da vida profissional } \\
\hline $\begin{array}{l}\text { 14- Considero que o meu trabalho é reconhecido e valorizado } \\
\text { pela empresa. }\end{array}$ & & & 1 & 5 & 19 \\
\hline $\begin{array}{l}15 \text { - Tenho um bom relacionamento com os meus colegas de } \\
\text { trabalho }\end{array}$ & & & & 6 & 19 \\
\hline \multicolumn{6}{|l|}{ Remuneração } \\
\hline $\begin{array}{l}\text { 16- A minha remuneração atual é adequada ao trabalho que } \\
\text { realizo. }\end{array}$ & & 3 & 2 & 9 & 11 \\
\hline 17 - Estou satisfeito com os benefícios oferecidos pela empresa. & & 2 & 3 & 15 & 5 \\
\hline \multicolumn{6}{|l|}{ Transporte dos funcionários } \\
\hline $\begin{array}{l}18 \text { - Encontro algum tipo de problema com o transporte casa- } \\
\text { empresa/empresa-casa. }\end{array}$ & 7 & 5 & 6 & 4 & 3 \\
\hline \multicolumn{6}{|l|}{ Segurança Profissional } \\
\hline 19 - Meu emprego é seguro na empresa, ou seja, não corro o & & 2 & 8 & 7 & 8 \\
\hline
\end{tabular}


risco de ser demitido sem motivo.

Fonte: dados da pesquisa, 2017.

Em relação ao fator vida profissional, essa variável foi dividida em cinco questões, que buscava investigar a satisfação ou insatisfação do colaborador, na sua vida profissional dentro da empresa. Percebe-se que os colaboradores estão satisfeitos em sua grande maioria com a sua vida profissional. Ao serem perguntados se sentem orgulho de trabalhar na empresa todos os questionados concordam ou concordam totalmente e também se sentem satisfeitos com a atividade que desempenham. Observou-se que a grande maioria dos colaboradores costuma indicar a empresa como alternativa de emprego para amigos e parentes. Segundo Drucker (2002) destaca que os gestores das organizações enfatizam "as pessoas são nosso maior ativo", ou seja, é transpassado ao colaborador a sua importância dentro da empresa, tornando assim o clima favorável ao trabalho e consequentemente, e orgulho de trabalhar na empresa (SANTOS; VRUBEL; AHRENS, 2016).

Quanto ao sucesso profissional, quatorze concordam e dez concordam totalmente, apenas um dos respondentes foi indiferente a essa pergunta. Essa questão evidencia que os colaboradores estão satisfeitos com o trabalho realizado, e que visam ainda uma perspectiva de crescimento. No ponto de vista dos cursos e treinamentos oferecidos para os melhores exercícios das atividades as respostas encontradas também foram satisfatórias, pois a maioria também se encontra satisfeito com os cursos e treinamentos que Ihes são oferecidos, sendo que quatorze concordam totalmente, demonstrando que os colaboradores conseguem exercer suas funções, através do aperfeiçoamento já adquirido oito concordam. Três respondentes discordam dessa afirmação, deixando em evidência a necessidade de aperfeiçoamento, adquirindo novos conhecimentos para o desempenho das atividades

Ao responder à pergunta "O ambiente de trabalho favorece a execução das minhas atividades na empresa" 19 colaboradores concordam totalmente 5 concordam e 1 colaborador ficou indiferente ao que Ihe foi questionado. Salienta-se que a organização está contida dentro de um ambiente o qual pode ser positivo ou negativo e que sofre diversas mudanças sejam elas derivadas das alterações do mercado, dos colaboradores, e que envolve desde o cliente até os gestores (SANTOS; VRUBEL; AHRENS, 2016).

Em relação aos colegas a pergunta utilizada foi "Tenho um bom relacionamento com meus colegas de trabalho" 19 respondentes concordaram totalmente e 6 concordam, o que deixa uma evidência que o ambiente de trabalho está sendo avaliado de forma positiva pela amostra estudada. Observa-se na variável em questão que os colaboradores estão satisfeitos e analisam de forma positiva o clima que encontram no ambiente de trabalho.

No que tange a assertiva " assistência aos funcionários" Essa variável apresentou um grau mais alto de insatisfação entre os colaboradores ao serem questionado se a empresa 
oferece assistência médica e odontológica adequadas às suas necessidades. Assim, 6 discordam totalmente, 7 discordam, 5 se mostraram indiferentes, 5 concordam e 2 concordam totalmente. Destaca-se que é por meio da remuneração compactuada com os benefícios que a empresa oferece que o colaborador consegue sanar suas necessidades básicas para sobrevivência, ajuda a conseguir atingir seus objetivos pessoais e sociais, sendo que essa é uma questão que precisa ser atentada pela empresa(SANTOS; VRUBEL; AHRENS, 2016).

A pergunta utilizada para avaliação de burocracia foi "A burocracia adotada na empresa favorece a execução das minhas atividades na empresa". Como resultado, obteve-se que 1 colaborador discorda totalmente, 2 discorda, 5 indiferentes, 12 concordam e 5 concordam totalmente. Essa variável, apresentada na tabela 4, demonstra que os respondentes em sua completa maioria, estão satisfeitos com a burocracia adota pela organização, e não encontra obstáculos para execução das suas tarefas. Em muitas organizações a burocratização é importante para o desenvolvimento de processos, porém, devido a mudanças significativa nesse contexto, as organizações precisam flexibilizar muitas vezes seus processos para se destacar no ambiente competitivo (SANTOS; VRUBEL; AHRENS, 2016).

Por meio da análise da cultura organizacional, tem-se um resultado positivo, pois 1 colaborador discorda, 3 foram indiferentes, 14 concordam e 7 concordam totalmente. Os aspectos pesquisados com relação à estrutura organizacional demonstram que os colaboradores estão satisfeitos com os seus líderes, concordando que as pessoas que ocupam os cargos hierárquicos são adequadas para a função que ocupam, e estão satisfeitos com a hierarquia as quais estão vinculados, sendo que somente um dos respondentes se mostrou indiferente a questão. Conforme Fernandes; Pedroso (2010) "a cultura de uma empresa determina a forma como funciona um clima organizacional de acordo com manifestações linguísticas e sociais, então se acredita que a cultura é fator determinante de sucesso de uma organização[...]".

A variável em questão busca mensurar o sentimento de valorização que o colaborador sente com relação a sua vida profissional, ao serem perguntados "Considero que o meu trabalho é reconhecido e valorizado pela empresa", os colaboradores demonstram que se sentem valorizados e encontram reconhecimento por parte da empresa. Observa-se também que os respondentes têm um bom relacionamento com os colegas de trabalho, o que demonstra que o clima entre os colegas é de contentamento. Aponta-se que é por meio do reconhecimento que a empresa tem para com seus colaboradores que os mesmos conseguem atingir seus objetivos pessoais, demostrando sucesso e sentindo-se reconhecidos (SANTOS; VRUBEL; AHRENS, 2016).

Para a variável remuneração o estudo demonstra que a maioria dos colaboradores concordam ou concordam totalmente que a remuneração que lhes é oferecida está adequada 
com a função que desempenham, sendo que apenas três colaboradores não concordam e dois foram indiferentes ao questionamento. A variável também buscou identificar se os benefícios oferecidos pela empresa estão agradando seus profissionais através da pergunta "Estou satisfeito com os benefícios oferecidos pela empresa", 15 colaboradores concordam e 5 concordam totalmente, 2 discordam e 3 estão indiferentes ao questionamento.

Os respondentes têm opiniões diversas na variável "transporte dos funcionários". Ao serem questionados se encontram algum problema no transporte casa/empresa ou empresa/casa, 7 discordaram totalmente, 5 discordaram, 6 foram indiferentes 4, concordaram e 3 concordam totalmente, o que mostra que a minoria dos colaboradores encontra algum tipo de problema com o seu deslocamento para a empresa ou da empresa para casa. Com relação à segurança profissional os colaboradores estão satisfeitos, ou seja, não se sentem ameaçados em perderem o emprego sem motivos. O número de colaboradores que se mostraram indiferentes ao questionamento foi alto em relação aos questionamentos anteriores, o que não pode ser identificado se existe algum descontentamento nessa variável. Apenas dois colaboradores não concordam que o emprego está seguro.

\section{FATORES EXTERNOS DE INFLUÊNCIA NO CLIMA ORGANIZACIONAL}

O levantamento de fatores externos, buscou identificar variáveis que possam influenciar no clima organizacional, ou seja, variáveis que não estão dentro da organização mas que possam afetar o estado de espírito dos colaboradores, trazendo algum tipo de desmotivação que afetem o clima vivido na empresa.

Tabela 3: Fatores externos da influência da liderança no clima organizacional

\begin{tabular}{|c|c|c|c|c|c|}
\hline & 1(DT) & 2(D) & $3(1)$ & $4 \mathrm{C}$ & $5(\mathrm{CT})$ \\
\hline \multicolumn{6}{|l|}{ Convivência familiar; férias e lazer; investimento e despesas familiares } \\
\hline 20- Tenho um bom relacionamento com a minha família. & & & & 10 & 15 \\
\hline \multicolumn{6}{|l|}{ 21- No meu tempo livre faço atividades que eu gosto. } \\
\hline $\begin{array}{l}\text { 22- Estou satisfeito com que estou podendo proporcionar à minha } \\
\text { família. }\end{array}$ & & & 1 & 9 & 15 \\
\hline \multicolumn{6}{|l|}{ Política e Economia } \\
\hline 23- Os acontecimentos políticos costumam afetar meu humor. & 1 & 3 & 14 & 4 & 3 \\
\hline 24- As crises econômicas alteram o meu estado de ânimo. & 2 & 3 & 14 & 4 & 2 \\
\hline \multicolumn{6}{|l|}{ Saúde } \\
\hline 25 - Estou satisfeito com o meu estado físico. & & 2 & 3 & 12 & 8 \\
\hline 26 - Estou satisfeito com o meu estado mental. & & & & 12 & 13 \\
\hline \multicolumn{6}{|l|}{ Segurança Pública } \\
\hline 27 - Estou satisfeito com o atual estágio da segurança pública. & 7 & 10 & 4 & 2 & 2 \\
\hline \multicolumn{6}{|l|}{ Situação Financeira } \\
\hline 25 - Estou satisfeito com o meu estado físico. & & 2 & 3 & 12 & 8 \\
\hline 26 - Estou satisfeito com o meu estado mental. & & & & 12 & 13 \\
\hline
\end{tabular}




\begin{tabular}{|c|c|c|c|c|c|}
\hline \multicolumn{6}{|l|}{ Time de futebol } \\
\hline 30 - Estou satisfeito com o time de futebol para o qual eu torço. & 1 & 1 & 6 & 5 & 12 \\
\hline \multicolumn{6}{|l|}{ Vida social } \\
\hline 25 - Estou satisfeito com o meu nível social. & & & 2 & 17 & 6 \\
\hline 26 - Estou satisfeito com o meu convívio social. & & & 1 & 18 & 6 \\
\hline
\end{tabular}

Fonte: dados da pesquisa, 2017.

As variáveis convivência familiar, férias e lazer e investimentos e despesas familiares estão de um modo geral interligadas, e servem para demonstrar a influência que as questões familiares podem ter dentro do ambiente organizacional. Nas variáveis em questão pode-se perceber que a maioria dos colaboradores estão bem resolvidos nos questionamentos ao que foram submetidos. No que diz respeito a convivência familiar, 22 dos respondentes concordam totalmente e 3 concordam, o que evidência que os colaboradores tem boas relações familiares. Em seu tempo livre direcionado a fazer atividades que gostam 17 concordam totalmente, 6 concordam e 3 são indiferentes, demonstrando que grande parte se sente satisfeito com as atividades desempenhadas para o seu lazer. Na questão "Estou satisfeito com que estou podendo proporcionar à minha família", 2 colaboradores discordam, 1 indiferente, 12 concordam e 10 concordam totalmente.

Pode-se observar que os respondentes ficaram divididos em suas respostas, mas que na sua maioria se sentem indiferentes nos assuntos relacionados a política e economia. $\mathrm{Na}$ questão "Os acontecimentos políticos costumam afetar meu humor", 1 colaborador discorda totalmente, 3 discordam, 14 indiferentes, 4 concordam e 3 concordam totalmente. As crises econômicas também não são fatores de influência externa predominante para os respondentes, pois ao serem perguntados se "As crises econômicas alteram o meu estado de ânimo", 5 colaboradores discordam totalmente ou discordam, 14 se sentem indiferentes à está questão e 6 concordam ou concordam totalmente que possam sofrer alguma influência no seu estado de ânimo.

A saúde pode ser um fator de grande influência externa, pois pode, além de transformar a rotina dos colaboradores com faltas ao trabalho, também diminuir o seu rendimento em suas atividades laborais. Nessa variável, a amostra estudada foi questionada se sente satisfeito com o seu estado físico e metal, o que pode ser observado que somente dois colaboradores não se sentem satisfeitos com seu estado físico e 3 foram indiferentes a essa questão, os demais demonstram-se contentes. Em relação ao seu estado mental, todos os questionados deram respostas satisfatórias, sendo que 12 concordam e 13 concordam totalmente demonstrando que estão satisfeitos com seu estado mental, o que leva a acreditar que não se sentem carregados psicologicamente.

A questão abordada nesse tema buscou identificar se os colaboradores estão se sentindo seguros com a atual segurança pública. O que pode-se observar, é que uma minoria 
dos questionados se sente satisfeito. Em sua grande maioria demonstram insatisfação com o atual estágio de segurança pública.

Ao serem questionados se "Estou com a minha situação financeira em ordem", 12 colaboradores concordam e 8 concordam totalmente, sendo que somente 5 dos respondentes não se sentem satisfeitos com sua atual situação financeira. No que diz respeito ao patrimônio, 7 colaboradores demonstram-se insatisfeitos com os bens que possuem, 2 são indiferentes e 16 deram respostas satisfatórias, como pode ser observado na Tabela 15.

Na variável "Estou satisfeito com o time de futebol para o qual eu torço". O que pode ser observado é que a maioria dos respondentes se sente satisfeitos com o time escolhido para torcer. Na variável vida social o grau de satisfação dos questionados foi elevado como demonstra a Tabela 3. Esse resultado indica que os colaboradores estão contentes com a sua classe social e com o convívio dentro da sociedade.

Com base nesses resultados, constata-se uma boa relação com os liderados com objetivo de apoio de orientação, proporciona bons líderes, e, consequentemente, um clima organizacional positivo. Sendo a liderança, um fator que influencia no clima e sendo está eficaz traz êxito para a organização com uma equipe mais comprometida e engajada.

A boa relação com o liderado, visando apoio e orientação fará com que a função do líder traga êxitos à organização. Originando climas positivos para o desenvolvimento do comportamento dos liderados, como consequência a equipe pode se manter eficaz e motivada para um bom resultado (ALMEIDA et al., 2017).

Na Tabela 4, apresenta-se os estilos de liderança.

\section{ESTILOS DE LIDERANÇA}

Tabela 4: Estilos de liderança

\begin{tabular}{|c|c|c|c|c|c|}
\hline Assertivas & 1 (DT) & $2(D)$ & $3(1)$ & $4(C)$ & $5(\mathrm{CT})$ \\
\hline 1 - O gestor é receptivo às sugestões e mudanças. & 1 & 1 & 1 & 14 & 8 \\
\hline $\begin{array}{l}2 \text { - O gestor da empresa toma decisões em nome do grupo } \\
\text { sem permitir participações nas decisões. }\end{array}$ & 1 & 9 & 7 & 4 & 4 \\
\hline $\begin{array}{l}3 \text { - O gestor não interfere nos processos decisórios da nossa } \\
\text { área de atuação. }\end{array}$ & & 11 & 3 & 8 & 3 \\
\hline $\begin{array}{l}4 \text { - Sempre sou consultado pelo meu gestor na tomada de } \\
\text { decisões que dizem respeito a minha área. }\end{array}$ & & 4 & 7 & 12 & 2 \\
\hline $\begin{array}{l}5 \text { - Os fatos importantes que ocorrem na empresa nunca são } \\
\text { informados pelo seu gestor. }\end{array}$ & & 15 & 5 & 2 & 3 \\
\hline $\begin{array}{l}6 \text { - Sempre que é necessário me afastar da empresa, não é } \\
\text { necessário comunicação prévia a meu gestor. }\end{array}$ & 3 & 12 & 4 & 1 & 5 \\
\hline
\end{tabular}

Fonte: dados da pesquisa, 2017.

Para definir o estilo de liderança que é predominante na empresa foram utilizadas seis 
questões como mostra a Tabela 4. Essas questões foram utilizadas para identificar se a liderança na empresa se caracteriza por ser autocrática, democrática e liberal. Observa-se que a liderança predominante na organização é a liderança democrática, onde os colaboradores sentem-se à vontade no que diz respeito a decisões e sugestões e no sentido de participações dentro da organização. Com fatores referentes a comunicação, os respondentes em sua grande maioria demonstram que são informados das decisões importantes que possam ocorrer dentro da empresa. A participação e a liberdade que os colaboradores demonstram sentir no clima da empresa, não fazem com que o gestor desconheça os fatos importantes de todos os setores e nem dá ao funcionário liberdade de tomar decisões sem o consentimento do seu gestor.

Salienta-se que não existe um estilo de liderança mais apropriado, mas deve-se atentar para um estilo que favoreça o clima, ajustando a cultura, aos objetivos da empresa e que se adapte a atual situação da organização (WENSKI; SOAVINSKY, 2013). Fazer com que os colaboradores trabalhem em equipe é uma tarefa desafiadora e o líder deve administrar seu estilo de liderança, ora não permitindo que os liderados participem das decisões tomadas, ora permitiOndo que os liderados tomem a maior parte das decisões, ou ainda, líderes que incentivem os funcionários a participarem das decisões (ALMEIDA et al., 2017).

\section{ANÁLISE DE REGRESSÃO LINEAR SIMPLES}

Para analisar a influência da liderança no clima organizacional foi utilizada a técnica de regressão linear simples que, teve como variável independente os estilos de liderança e como variável dependente a nota geral dada pelos colaboradores a respeito do clima organizacional da empresa. Os resultados são apresentados na Tabela 5.

Tabela 5: Influência da liderança no clima organizacional

\begin{tabular}{l|l|l|l|l}
\hline Tipo de liderança & Coef. & Std. Err. & t & P>t \\
\hline Democrática & 0.386997 & 0.153129 & 2.53 & 0.019 \\
\hline Autocrática & 0.160973 & 0.146483 & 1.1 & 0.284 \\
\hline Liberal & 0.065397 & 0.117694 & 0.56 & 0.584 \\
\hline
\end{tabular}

Fonte: dados da pesquisa, 2017.

Observa-se que a única variável que apresentou significância estatística com p-value < 0,5 foi a liderança democrática, o que demonstra que a liderança democrática afeta positivamente o clima organizacional da empresa, ou seja, quanto mais democrática for a liderança, melhor será o clima organizacional. As outras duas lideranças não obtiveram significância estatística com $p$-value $>0,5$, sendo assim não é possível fazer nenhuma inferência, ou seja, não se pode falar que as lideranças autoritária e liberal afetam o clima.

As notas demonstram que os colaboradores estão satisfeitos em sua maioria com o clima e que poder participar e ser ouvido dentro da organização faz com que se sintam mais 
valorizados, o que consequentemente pode trazer um melhor desempenho em suas atividades profissionais. Esses resultados estão alinhados à ideia de que lideranças democráticas geram um clima organizacional melhor. Neste sentido, Carvalho e Melo (2008) argumentam que para criar um ambiente saudável, é essencial saber escutar os indivíduos, detectando os dilemas que possam estar dificultando o crescimento das relações pessoais e organizacionais e estabelecer canais de diálogo. Diante deste clima, o colaborador sente-se confortável para conversar com a liderança, pois entende que o líder irá buscar soluções, realizando adequações e reparando erros quando for necessário. Carvalho e Melo (2008) mencionam ainda que quem estabelece o ambiente é o líder e sua maneira de liderar. O convívio entre líder e os liderados, deve ser excepcional, tendo em vista que o líder é um fator fundamental para motivar, estabelecer boas relações na organização e influenciar o grupo a prosperar no trabalho com mais eficiência. Do contrário, se as relações pessoais forem prejudicadas, haverá atuação negativa de modo direto no processo organizacional.

\section{CONSIDERAÇÕES FINAIS}

O presente estudo teve como objetivo geral identificar a influência do estilo de liderança no clima organizacional em uma empresa de defensivos agrícolas do Rio Grande do Sul. Identificou-se que as variáveis questionadas externas e internas na sua maioria são satisfatórias para os colaboradores, onde demonstram que o clima da empresa é bom e que a maioria dos respondentes sentem-se seguro no emprego e tem um bom relacionamento com os colegas, e com os seus familiares. Encontrou-se como ponto negativo, a insatisfação de alguns colaboradores com assistência médica e odontológica que é oferecido aos colaboradores, mas não sendo um fator relevante de insatisfação para todos os colaboradores. As notas dadas pelos questionados a respeito do clima organizacional ficaram todas acima de oito, o que demonstra contentamento na totalidade da amostra.

A pesquisa identificou que o estilo predominante na empresa é o estilo democrático, onde os funcionários sentem-se à vontade para expressar suas opiniões e consideram que existe comunicação na tomada de decisões. Os resultados demonstraram que apenas a liderança democrática afeta significativamente o clima organizacional. As lideranças autocrática e liberal não apresentaram significância na pesquisa, não podendo dizer que elas exerçam algum tipo de influencia dentro da empresa. A positividade da nota demonstra que a liderança democrática que é exercida na empresa influencia positivamente para a realização das tarefas na busca para o sucesso da mesma. O estudo evidenciou que os colaboradores tendem a ficar na empresa ao longo dos anos, o que indicou que a liderança exercida agrada os funcionários.

A pesquisa apresentou algumas limitações, como a amostra estudada sendo muito pequena, para considerar uma influência importante no clima organizacional. Também não se 
pode afirmar que todos os respondentes foram sinceros em suas repostas e que não se sentiram constrangidos em fazer reclamações sobre a empresa, onde ganham o seu sustento.

Para estudos futuros sugere-se que os sócio proprietários também sejam submetidos a participar da pesquisa, tentando identificar o tipo de liderança que acreditam que exercem na empresa e qual pontos sejam possíveis de melhorias, também pode-se buscar um estudo mais aprofundado com relação aos benefícios e treinamentos que os colaboradores consideram importantes para a realização de suas tarefas profissionais e melhor satisfação pessoal.

\section{REFERÊNCIAS}

ABELHA, D. M.; CARNEIRO, P. C. C.; CAVAZOTTE, F. S. C. N. Liderança transformacional e satisfação no trabalho: avaliando a influência de fatores do contexto organizacional e características individuais. Revista Brasileira de Gestão de Negócios, v. 20, n. 4, p. 516-532, 2018.

ALMEIDA, A. B.; GARCIA, A. S. T.;SILVA, A. M.; ANDRADE, L. R.; ALVES, N. P.;SILVA RABELO, M. H.; CHAVES, D. V. M. A Influência da Liderança no Clima Organizacional. Revista Acadêmica Conecta FASF, v. 2, n. 1, 2017.

BARBIERI, Ugo Franco. Gestão de Pessoas nas Organizações-Conceitos Básicos e Aplicações. São Paulo: Atlas, 2016.

BASS, B. M. (1985). Leadership and performance beyond expectations. New York: Free Press.

BISPO, Carlos A.F. Um novo modelo de pesquisa de clima organizacional.

Produção,v.16,n.2,p.258-273, Maio/Ago.2006.

BIEGELMEYER, U.; DALBERTO, M.; CRACO, T.; CAMARGO, M. E.; BERNARDI, F. C.; FERNANDES, A. M. Fatores internos e externos influenciam o clima organizacional. Revista ESPACIOS| Vol. 36 (№ 23) Año 2015, 2015.

BURNS, J. M. Leadership. New York: Harper \& Row Publishers, 1978.

CARVALHO, I. N. F.; MELO, N. P. Cultura e Clima organizacional: ingredientes para o sucesso das organizações públicas e privadas. Artigo apresentado ao Instituto de Desenvolvimento Econômico, Rural e Tecnológico Dados da Amazônia. Manaus: Faculdade Gama Filho, 2008

CODA, R. Pesquisa de clima organizacional e a gestão estratégica de recursos humanos. In: BERGAMINI, Cecilia W.; CODA, Roberto. Psicodinâmica da Vida Organizacional: motivação e liderança. 2.ed. São Paulo:Atlas 1997

COSTA, A. L.; SILVA, R. C. O Papel e a Influência das Lideranças no Clima para Serviços em Restaurantes. Revista de Carreiras e Pessoas, v. 10, n. 1, p. 103-127, 2020. 
DRUCKER, P. F. Profissão de administrador. Cengage Learning Editores, 2002.

FERNANDES, lara Oliveira; PEDROSO, Reginaldo. Cultura Organizacional: A influência da cultura nas organizações. Revista Olhar Científico, v. 1, n. 1, 2010.

GIUSTINA, K. A. D.; GASPARETTO, V.; LUNKES, R. J. Efeito dos Estilos de Liderança nos Sistemas de Controle Gerencial e no Desempenho Organizacional. Revista Capital Científico Eletrônica, v. 18, n. 1, p. 64-81, 2020.

GUERRA, R.M.A; TARTAROTTI, S.; CAMARGO, M. E. Liderança transacional e transformacional: uma análise fatorial exploratória sobre as variáveis influenciadoras. Revista Eletrônica de Administração e Turismo, v. 12, n. 6, p. 1482-1502, 2018.

HAIR JR, J. F. et. Al; Fundamentos de Métodos de Pesquisa em Administração. Porto Alegre: Bookman, 2005.

HITT, M. A.; MILLER C. C.; COLELLA A. Comportamento Organizacional: Uma Abordagem Estratégica. Ed. LTC, 2007.

LIMA, T. B.; GOMES, S. L. Os Estilos de Liderança na Gestão Hoteleira: um estudo em hotéis da orla de João Pessoa-PB. Revista Organizações em Contexto, v. 13, n. 26, p. 19-71, 2017.

MATTOS, C. A. C. Clima organizacional sob a perspectiva dos gestores de Instituições Federais de Ensino: uma investigação multivariada. Revista Organizações em Contexto, v. 15, n. 30, p. 53-81.

RADAELLI, A. L. O estilo de liderança presente na empresa Sucesso LTDA. Universidade Federal do Rio Grande do Sul. Escola de Administração. Curso de Administração.

ROBBINS, S. P. Comportamento Organizacional. 11. ed. São Paulo: Pearson Prentice Hall, 2005.

RODRIGUES, S. A.; SILVA, M. D. S.; FRADE, C. M.; SOUSA, F. R. L. Estilos de Liderança de Professores Universitários: Um Estudo de Caso em uma Instituição de Ensino Pública . Gestão \& Conexões, v. 8, n. 2, p. 84-104, 2019.

SANTOS, Â. A.; VRUBEL, C. A.; AHRENS, R. B. Análise do clima organizacional: Estudo de caso em uma empresa de engenharia civil em Ponta Grossa-PR. Revista ESPACIOS| Vol. 37 (№ 24) Año 2016, 2016.

SOBRAL, F.; FURTADO, L.; ISLAM, G. Humor como Catalisador e Neutralizador da Eficácia da Liderança . Revista de Administração de Empresas, v. 59, n. 5, p. 313-326, 2019.

SOTO, E. Comportamento organizacional: o impacto das emoções. tradução técnica de Jean Pierre Marras. São Paulo: Cengage Learning, 2010.

SOUSA, R. L.; CAPPELLOZZA, A. Os Efeitos dos Estilos de Liderança e Vício em Internet no Tecnoestresse. Revista Administração em Diálogo-RAD, v. 21, n. 1, p. 39-62, 2019. 
VERSIANI, F.; CAEIRO, M.; MARTINS, M.; CARVALHO NETO, A. Características De Liderança Das Mulheres Empreendedoras: Um Estudo De Caso No Setor De Serviços. Revista de Administração da UNIMEP, v. 17, n. 1, 2019.

WENSKI, A. H. C. M.; SOAVINSKI, E. R. W. A influência do líder no clima organizacional. Percurso, v. 1, n. 13, p. 299-321, 2013. 